\title{
As principais Fake News sobre a pandemia da Covid-19 no Brasil
}

\section{The main Fake News about the Covid-19 pandemic in Brazil}

Daniela Bezerra Sirtoli1 ${ }^{1}$, Gisela Daleva Costa ${ }^{2}$

\section{RESUMO}

A COVID-19 é uma doença causada pelo novo coronavírus, sendo denominada também como SARS-CoV-2, que pode variar desde infecções assintomáticas a quadros graves. Esse termo vem do inglês "fake news", que significa "notícias falsas" em português, popularizou-se mundialmente e seu significado é ligado às informações, de qualquer natureza, que são falsas, inventadas ou manipuladas e publicadas, em sua grande maioria, na internet. Com isto, o Ministério da Saúde brasileiro capturou as notícias falsas e as classificou como Fake News. Assim, este trabalho tem como objetivo evidenciar todas as fake news que estão publicadas na página "Saúde sem fake news" do Ministério da Saúde. O estudo de caráter descritivo contou com o levantamento das notícias falsas sobre o coronavírus. Foram obtidas 79 notícias. Estas, após a coleta de dados, foram repassados a uma tabela elaborada pelas autoras, para organização das informações. A COVID-19 ainda é muito recente e suas respostas ainda estão sendo buscadas. Por isso, é tão importante diferenciar o que é verdade do que não é. Continue cuidando da sua saúde e da saúde de seus próximos e nunca compartilhe notícias alarmistas e conspiratórias, de conteúdo e fontes duvidosas.

Palavras-chave: Covid-19. Fake News. Pandemia. Notícias.

\section{ABSTRACT}

COVID-19 is a disease caused by the new coronavirus, also being called SARS-CoV-2, which can range from asymptomatic infections to severe conditions. This term comes from the English "fake news", which means "false news" in Portuguese, has become popular worldwide and its meaning is linked to information, of any nature, which is false, invented or manipulated and published, in its vast majority, on the Internet. With this, the Brazilian Ministry of Health captured the fake news and classified it as Fake News. Thus, this work aims to highlight all the fake news that are published on the "Health without fake news" page of the Ministry of Health. The descriptive study included a survey of false news about the coronavirus. 79 news items were obtained. These, after data collection, were transferred to a table created by the authors to organize the information. COVID-19 is still very new and its answers are still being sought. That's why it's so important to differentiate between what's true and what's not. Keep taking care of your health and the health of those around you and never share alarmist and conspiratorial news, content and dubious sources.

Keywords: Covid-19. Fake News. Pandemic. News
${ }^{1}$ Enfermeira Residente em Saúde da Familia e Comunidade da Universidade de Gurupi; Especialista em Vigilância Sanitária; Especialista em Terapia Intensiva; Especialista em Saúde Coletiva com Concentração em Monitoramento Avaliação Informação Estratégica.

E-mail:

danielabsirtoli@gmail.com

${ }^{2}$ Enfermeira, Mestre em Medicina Tropical. 


\section{INTRODUÇÃO}

A COVID-19 é uma doença causada pelo novo coronavírus, sendo denominada também como SARS-CoV-2, que pode variar desde infecções assintomáticas a quadros graves. A Organização Mundial de Saúde (OMS), explica que $80 \%$ dos pacientes com COVID-19 podem estar assintomáticos ou oligossintomáticos e, aproximadamente, $20 \%$ dos casos diagnosticados vão precisar ser hospitalizados por apresentarem dificuldade respiratória. O período de incubação é estimado entre 1 a 14 dias, com mediana de 5 a 6 dias (MINISTÉRIO DA SAÚDE, 2020).

No dia 11 de março de 2020, Tedros Adhanom, diretor geral da Organização Mundial de Saúde (OMS), declarou que a organização elevou o estado da contaminação à pandemia de Covid-19. Com isso cientistas e autoridades da área da saúde buscam respostas e soluções para esclarecer as pessoas acerca de uma nova pandemia. Ao mesmo tempo inúmeras mensagens alarmistas e conspiratórias se multiplicam por meio da internet. Desde então a disseminação de fake news ligadas à pandemia tem aumentado. Segundo Tedros Adhanom Ghebreyesus, esse é um fenômeno perigoso, pois o elevado número de casos do vírus está sendo diretamente proporcional à incidência de informações equivocadas ou falsas sobre o assunto (UNIVERSIDADE FEDERAL DE PERNAMBUCO, 2020).

Esse termo vem do inglês "fake news", que significa "notícias falsas" em português, popularizou-se mundialmente e seu significado é ligado às informações, de qualquer natureza, que são falsas, inventadas ou manipuladas e publicadas, em sua grande maioria, na internet. A distribuição de notícias falsas e a desinformação durante a pandemia aumentam o sentimento de insegurança da sociedade, uma vez que a desconfiança quanto à veracidade do conteúdo recebido se junta à preocupação com a crise sanitária e econômica que vivemos (MATTOS FILHO,2020).

Fake News são informações e notícias falsas postadas nas mídias sociais, o que conduziu a diversos compartilhamentos, originando uma rede de conteúdo e pseudoinformações. Com os avanços tecnológicos, estas notícias falsas são postadas nas redes sociais, de forma rápida e multiplicada entre a população, que, em linguagem metafórica, funciona como um vírus que contamina a comunicação e promove ações e comportamentos contrários às orientações das autoridades técnicas no campo da saúde (MERCEDES, 2020). 
Em meio à pandemia do novo coronavírus as Fake News só estão aumentando. Por isso, a preocupação não deve ser apenas de conter o vírus, mas também em conter informações mentirosas e prejudiciais. Nesse aspecto, um desafio para qualquer pessoa é identificar informações falsas o problema é que muitas delas vêm acompanhadas de trechos de informações corretas o que faz ser tão perigosas quanto a própria doença. Ter acesso à informação verdadeira é essencial para garantir o direito à saúde, isto é, permitir que as pessoas possam se prevenir adequadamente do vírus e saber quais medidas tomar em caso de contaminação (MERCEDES, 2020; MATTOS FILHO, 2020).

Com a necessidade do isolamento social, o uso diário das redes socias aumentou de maneira significativa, tornando difícil reconhecer quais notícias são verdades e quais são falsas. Diversas notícias foram publicadas nos meios de comunicação e consumidas pela população, em geral, sendo muitas delas falsas. Com isto, o Ministério da Saúde brasileiro capturou as notícias falsas e as classificou como Fake News. Assim, este trabalho tem como objetivo evidenciar todas as fake news que estão publicadas na página "Saúde sem fake news" do Ministério da Saúde.

\section{MATERIAIS E METODOS}

O estudo de caráter descritivo contou com o levantamento das notícias falsas sobre o coronavírus divulgadas na página "Saúde sem fake news" do Ministério da Saúde. O período evidenciado foi de janeiro de 2020 até setembro de 2021. Foram obtidas 79 notícias. Estas, após a coleta de dados, foram repassados a uma tabela elaborada pelas autoras, para organização das informações.

O canal SAÚDE SEM FAKE NEWS é um canal do Ministério da Saúde, de recebimento e envio de mensagens instantâneas, via WhatsApp, para combater as chamadas "Fake News" sobre saúde O canal tem como objetivo, exclusivamente, esclarecer informações que a população enviar, com o intuito de confirmar se estas se tratam de verdades ou não. É um canal direto com o Ministério da Saúde, de maneira a desmentir as chamadas "Fake News", ou "notícias falsas", que circulam livremente por mensagens via redes sociais (MINISTÉRIO DA SAÚDE, 2021).

De acordo com o Ministério da Saúde (2021), para combater as Fake News sobre a saúde de forma inovadora, foi disponibilizando um número de WhatsApp para envio de mensagens da população. Lembrando que o canal não será um serviço de atendimento ao cliente ou de tirar dúvidas dos usuários, mas um espaço exclusivo para receber 
informações virais. Que em seguida serão apuradas pelas áreas técnicas e respondidas oficialmente se são verdade ou mentira. Todo cidadão poderá enviar gratuitamente mensagens com imagens ou textos que tenha recebido nas redes sociais para confirmar se a informação é verdadeira, antes de continuar compartilhando.

O fluxo de atendimento ocorre da seguinte maneira o cidadão(ã) envia a mensagem sobre saúde que recebeu e deseja confirmar se é verdadeira ou falsa. A mensagem deve conter seu nome completo, município e estado de residência e a mensagem que deseja averiguar. Em seguida, a equipe multimídia do Ministério da Saúde enviará a dúvida à área técnica responsável pelo assunto em questão. A equipe da área técnica do Ministério da Saúde analisará a mensagem e fará a apuração do assunto, para, então, enviar a resposta para a equipe multimídia do Ministério da Saúde. A equipe multimídia do Ministério da Saúde responderá a ocorrência ao(à) cidadão(ã) com um selo de "isto é notícia falsa" ou de "isto é notícia verdadeira". Por fim a dúvida e a resposta serão publicadas no Portal Saúde e nos perfis oficiais do Ministério da Saúde nas redes sociais. Os dados pessoais do(a) cidadão(ã) não serão divulgados. Todas as ocorrências respondidas poderão ser encontradas no site saude.gov.br/fakenews (MINISTÉRIO DA SAÚDE, 2021).

\section{RESULTADOS}

QUADRO 1- Títulos das Fake News, segundo o Banco de Dados do Ministério da Saúde (BR). Brasil, 2021.

\section{TITULOS DAS FAKE NEWS}
1 Declaração ministro Pazuello sobre atestados de óbitos
2 Vacina da gripe aumenta risco de adoecer por coronavírus
3 Máscaras sem qualidade distribuídas pelo Ministério da Saúde
4 Software das UPAS obrigam registro de coronavírus
5 Máscaras de doação da China são contaminadas com coronavírus
6 Número de óbitos por COVID é de 946
7 Café previne o coronavírus
8 Fumar aumenta o risco da forma grave de coronavírus
9 Alimentos alcalinos evitam coronavírus
10 Medicamento para COVID-19
11 Beber água de 15 em 15 minutos cura o coronavírus
12 Rússia anuncia cura para coronavírus 
13 Chá de limão com bicarbonato quente cura coronavírus

14 Áudio do ministro da Saúde sobre o pico de infecção do coronavírus

15 Ministro da Saúde pede para compartilhar áudio com informações do coronavírus

16 Aplicativo Coronavírus-SUS, do Governo do Brasil, é inseguro

17 Governo do Brasil anuncia vacina do coronavírus

18 China anuncia vacina para coronavírus

19 Beber muita água e fazer gargarejo com água morna, sal e vinagre previne coronavírus

20 Todos os países adotam as mesmas medidas para enfrentar o coronavírus

21 Pesquisa publicada por cientistas chineses diz que coronavírus tornará a maioria dos pacientes do sexo masculino infértil

Verdades e mentiras do CREMERJ para coronavírus

Tomar ou bebidas quentes para matar o coronavírus

24 Coronavírus morre a $26^{\circ} \mathrm{C}$

25 Água ou chá quente mata o coronavírus

26 Beber água quente mata o coronavírus

27 Ministério da Saúde recomenda quarentena aos viajantes assintomáticos para coronavírus

Coronavírus fica vivo por 9 dias

29 Receita de coco que cura coronavírus

30 Caso de coronavírus confirmado no Ceará

31 Caso de coronavírus confirmado no Piauí

32 Vitamina C cura coronavírus, que veio dos animais, e água com limão que cura câncer

33 Utilizar álcool em gel nas mãos para prevenir coronavírus altera bafômetro nas blitz

34 Bombeiro afirma que há mais de 58 casos de coronavírus no Brasil

35 Coronavírus veio dos animais

36 Álcool em gel é a mesma coisa que nada

37 E-mail com informações de que chá de erva doce cura coronavírus

38 Fibrose nos pulmões ao respirar e coronavírus

39 Coronavírus veio do inseticida

40 Paciente com coronavírus curada em 48h com medicamentos de AIDS

41 Muitos casos confirmados de coronavírus no Brasil

42 Coronavírus pode ser curado com tigela de água de alho recém-fervida 
43 Coronavírus vem do morcego

45 Caso de coronavírus em casal na Feira dos Importados em Brasília

46 Chá de erva doce e coronavírus

47 Tribunal chinês para matar 20 mil pacientes com coronavírus

48 China cancelou todos os embarques de produtos por navio até março

49 Cura contra o coronavírus

50 Médicos tailandeses curam coronavírus em 48h

51 Plástico bolha e o novo coronavírus

52 Chá de abacate com hortelã previne coronavírus

53 Semelhança do vírus HIV com o coronavírus

54 Situação fora de controle: novo coronavírus

55 Novo coronavírus causa pneumonia de imediato

56 Medicamentos eficazes contra o novo coronavírus

57 Novo coronavírus confirmado em Duque de Caxias

58 Novo coronavírus confirmado no Brasil

59 Novo coronavírus confirmado no Paraná

60 Dados sobre o novo coronavírus na China

61 Coronavírus atinge 3 estados brasileiros

62 Suspeita de coronavírus no Hospital de Santa Maria (DF)

63 Uísque e mel contra coronavírus

64 Óleos para combater coronavírus

65 Chá imunológico contra o novo coronavírus

66 Vitamina $\mathrm{C}+$ zinco e o novo coronavírus

67 Compras da China pela internet e o novo coronavírus

68 Carnaval será porta de entrada para o novo coronavírus

69 Médico falando sobre prevenção do novo coronavírus

70 Feira dos Importados em Brasília e o novo coronavírus

71 Vídeo - vitamina D e a prevenção do novo coronavírus

72 Notificação emergencial do Ministério da Saúde sobre novo coronavírus

73 Parar o carnaval por conta do novo coronavírus

74 Governo esconde números sobre novo coronavírus

75 Pesquisadores da UFRJ e o novo coronavírus

76 Foto da China e o novo coronavírus 
77 Sopa de morcego e o coronavírus

78 Chá de erva doce e o tratamento do novo coronavírus

79 Nova gripe fatal e chá de erva doce

Fonte: Elaborada pelas autoras, 2021.

\section{DISCUSSÄO}

Os políticos, empresas, organizações, gestores públicos e privados, jornalistas, profissionais da saúde, professores enfim toda sociedade depende de informação confiável para tomar decisões corretas. No entanto, não são todos que ao ler notícias conseguem diferenciar o verdadeiro do falso. As Fake News e a desinformação são, portanto, perigosas porque as decisões das pessoas serão guiadas por informações falsas ou mal compreendidas. Usando a comunicação como estratégia as notícias falsas possuem, em certa medida, aparência verídica e são disseminadas em grande escala com o intuito de obter ganhos ou trazer prejuízos a terceiros. Aproveitando da velocidade e interatividade da internet, as notícias falsas conseguem chegar a milhares de leitores em poucos minutos (MATTOS FILHO,2020).

As buscas na Internet com temas ligados à proteção e preservação da saúde buscam informações práticas, fundamentadas em evidências e aplicáveis a curto, médio ou longo prazo. A OMS define "infodemia" como várias informações inseguras sobre um determinado problema, em especial associadas às buscas reativas em tempos de grandes medos, o que causa dificuldades para solucionar os problemas e cria tumultos e desconfiança entre leigos (VASCONCELLOS, 2020).

Atualmente o fenômeno das fake news é um grande problema. Espalham-se com facilidade e rapidez, principalmente na internet, por meio das redes sociais. Para tentar explicar melhor esse fenômeno negativo existe dois tipos de notícias falsas, a primeira está relacionada à disseminação de informações por pessoas mal-intencionadas, que faz em favor dos próprios interesses. $\mathrm{E}$ a segunda diz respeito àquelas informações compartilhadas inocentemente, apesar de falsas. Um exemplo simples é a propagação de notícias sobre o uso de medicamentos que prometem curas "simples", mas que ainda não tiveram eficácia cientificamente comprovada, podendo acarretar sérios prejuízos à saúde (MATTOS, 2020).

Uma notícia falsa é a informação baseada na ausência ou na má-representação de fatos. Habitualmente, as fakes news são feitas com partes de notícias verdadeiras, ou seja, 
os fatos são retirados do contexto, as fontes não são confirmadas e há o exagero para tentar atrair o leitor. No Quadro 1, apresenta alguns tipos de Fake News e suas definições.

Quadro 1- As sete categorias das Fake News segundo First Draft

TIPOS DE FAKE NEWS

Sátira ou paródia

Falsa conexão

Conteúdo enganoso

Falso contexto

Conteúdo impostor

Conteúdo manipulado

\section{Conteúdo fabricado}

Fonte: Organizada pelas autoras.

\section{DEFINIÇÃO}

Não possui intenção de causar mal, mas tem potencial de enganar

Quando imagens, títulos e legendas dão falsas dicas do que realmente é o conteúdo que segue junto

Utilização de uma informação que causa engano sobre um assunto ou contra uma pessoa.

Quando um conteúdo verídico é compartilhado em um falso contexto.

Quando afirmações falsas são atribuídas a fontes reais, geralmente pessoas ou instituições.

Informação verdadeira manipulada para enganar as pessoas

Conteúdo total ou parcialmente falso com o objetivo de gerar desinformação e causar algum mal.

A ausência de legislação específica para esse tema leva à necessidade de regular e julgar, por meio de analogia, os casos levados ao Poder Judiciário. As recomendações para prevenção da Covid-10 continuam sendo lavar as mãos frequentemente com água e sabão, utilizar álcool em gel 70\%, usar máscaras, manter o distanciamento, evitar contato físico, higienizar bem os objetos de uso pessoal, se alimentar bem e se exercitar para manter uma boa imunidade. É primordial orientar toda a população para que não dissemine informações falsas, pois isso pode impedir que outra pessoa se previna de maneira adequada.

A desinformação sobre o COVID-19 proliferou amplamente nas redes sociais, desde a venda de falsas "curas", como gargarejar com limão ou água salgada e injetar alvejante em você mesmo, a falsas teorias da conspiração de que o vírus foi bioengenharia em um laboratório em Wuhan ou que a rede celular 5G está causando ou piorando os sintomas de COVID-19. Mas a desinformação sobre o COVID-19 não se limita a informações flagrantemente verdadeiras ou falsas, o que amplia o escopo do problema. Por exemplo, embora os danos e benefícios da hidroxicloroquina como um tratamento potencial estejam de fato sendo estudados, atualmente não há consenso científico sobre sua eficácia. Assim, mesmo decidir o que conta como desinformação sobre o COVID-19 é uma questão 
complicada. No entanto, está se tornando cada vez mais claro que a desinformação sobre o COVID-19 é um problema comum (VAN DER, 2020).

\section{CONSIDERAÇOES FINAIS}

O compartilhamento de fake news traz consequências danosas para a sociedade como um todo. Através da distribuição de falsas notícias não é raro observar episódios de linchamento, práticas discriminatórias, bem como histeria coletiva relacionada aos temas de saúde pública, segurança e educação, dentre outros. É necessário divulgar e recomendar onde buscar informações confiáveis e de qualidade sobre saúde. Uma das possibilidades de se combater as fakes news e deixar a população menos vulnerável é estimular um maior diálogo entre a ciência e a população, por meio da divulgação em grande escala das produções cientificas (MATTOS FILHO,2020).

Estamos vivendo tempos difíceis com crises, incerteza, ansiedade e pânico. Buscamos por informações para nos deixar mais seguros e tranquilos, uma vez que conhecimento é poder. Por esse motivo, devemos abraçar todo esse cenário com responsabilidade, verificando o que é verdadeiro e o que é falso, para o nosso bem e o bem da coletividade. A COVID-19 ainda é muito recente e suas respostas ainda estão sendo buscadas. Por isso, é tão importante diferenciar o que é verdade do que não é. Continue cuidando da sua saúde e da saúde de seus próximos e nunca compartilhe notícias alarmistas e conspiratórias, de conteúdo e fontes duvidosas.

\section{REFERENCIAS}

MATTOS, FILHO; Et Al. Fake news e desinformação em tempos de Coronavírus: promovendo o direito à informação de qualidade para efetivar o direito à saúde. 2020. Disponível em: < https://www.mattosfilho.com.br/EscritorioMidia/200526-paper-fakenews.pdf >. Acesso em 18 set. de 2021.

UNIVERSIDADE FEDERAL DE PERNAMBUCO. Manual de enfrentamento de fake news em tempos de covid-19. Recife, maio de 2020. Disponível em: < https://sites.ufpe.br/rpf/wp-content/uploads/sites/43/2020/05/Manual-de-enfrentamento-afake-news.pdf>. Acesso em 18 de set. de 2021.

MINISTÉRIO DA SAÚDE. Protocolo de Manejo Clínico para o Novo Coronavírus (2019nCoV). Brasília - $\quad$ DF 2020. Disponível em: <https://portalarquivos2.saude.gov.br/images/pdf/2020/fevereiro/11/protocolo-manejocoronavirus.pdf>. Acesso em 19 set. 2021. 
MERCEDES, Neto. Fake News no cenário da pandemia de covid-19. Cogitare enferm. 25: e72627, 2020. Disponível em: < https://revistas.ufpr.br/cogitare/article/view/72627/pdf>. Acesso em 19 set. 2021.

MINISTÉRIO DA SAÚDE. Saúde sem Fake News. 2021.Disponível em: <https://www.saude.gov.br/fakenews>. Acesso em 19 set. 2021.

VASCONCELLOS, Silva PR, Castiel LD. COVID-19, As fake news e o sono da razão comunicativa gerando monstros: a narrativa dos riscos e os riscos das narrativas. Cad. Saúde Pública 2020; 36(7):e00101920. Disponível em: <https://www.scielo.br/j/csp/a/d6ZXNpddtmjgNjRtKMDY4bR/?format=pdf\&lang=pt>. Acesso em 21 set. 2021.

VAN DER, Linden S, Roozenbeek J e Compton J. Inoculating Against Fake News About COVID-19. Frente. Psychol., 23 de outubro de 2020. Disponível em:< https://www.frontiersin.org/articles/10.3389/fpsyg.2020.566790/full>. Acesso em 21 set. 2021. 